\title{
Analysis of centromere co-orientation in intervarietal hybrids of common wheat (Triticum aestivum L.), by means of C-banding
}

\author{
Araceli Fominaya and \\ Nicolas Jouve
}

Department of Genetics, Faculty of Sciences, University of Alcalá de Henares, Apdo. 20. Alcala de Henares (Madrid), Spain.

The detection of intervarietal variation in $C$-banding pattern of meiotic $1 B, 4 B$ and $5 B$ chromosomes in $F_{1}$ hybrids of common wheat, Triticum aestivum L., permitted the analysis of interchromosomal affinity on the separation of their centromeres to opposite poles at first metaphase.

Testing meiotic configurations for centromere co-orientation, non-randomness was found, resulting from an excess of the type of distribution with the three chromosomes having the highest amount of heterochromatin going to the same pole. The centromeres that congregated predominantly together at the same pole were not derived from the same parent of the hybrids. Consequently, the predominance of that type of separation cannot be attributed to centromeric affinity.

\section{INTRODUCTION}

In general, it is assumed that different pairs of chromosomes are independent in respect of their distribution to opposite poles at first metaphase of meiosis. However, the direct demonstration of randomness in centromere orientation is difficult to do when the different chromosomes of each bivalent in one metaphase plate cannot be distinguished. Preferential segregation that is, the passing of a specific chromosome to a specific pole may be detected genetically, when genetic linkage or nonrandom genetic ratios between the genes located in different chromosomes is produced. The concept of "affinity" was originally elaborated by Michie (1953) and Wallace (1953) and has since been genetically analyzed in mouse (Michie, 1955; Parsons, 1959; Wallace, 1958 ; 1959; 1961), cotton (Wallace, 1960; 1965; Phillips, 1964), maize (Michel, 1970), parasitoid wasp Mormoniella vitripennis (Conner, 1966), and, yeast Saccharomyces cerevisiae (Lindegren and Shult, 1956; Shult and Lindegren, 1957; Lindegren et al., 1962; Hwang, 1966).

The analysis of interdependent co-orientation of centromeres can be made when it is possible to distinguish the chromosomes of both parents in hybrids. In some cases the problem has been alleviated using hybrids involving chromosomes cytomorphologically marked by knobs, size differences, telocentrics, such as in maize (Rhoades, 1942; Rhoades and Dempsey, 1966), tobacco (Sficas, 1963), cotton (Phillips, 1964) and ryegrass (Rees and Jones, 1967). The orientation of centromeres of rye chromosomes in a rye-wheat derivative involved in bivalent and quadrivalent associations was investigated using C-banding by Naranjo and Lacadema (1979) who observed a random distribution of the centromeres to the poles.

The present study is undertaken to provide evidence on the existence of affinity in intervarietal hybrids in common wheat. Intervarietal differentiation in the $\mathrm{C}$-banding pattern affecting three bivalents $(1 \mathrm{~B}, 4 \mathrm{~B}$ and $5 \mathrm{~B})$ is used as an identifying feature.

\section{MATERIALS AND METHODS}

The plant material studied was the following:

(i) $3 F_{1}$ intervarietal hybrids of common wheat: "Alonso Peña 113" $\times$ "Chinese Spring", "Alonso Peña 113" $\times$ "Alonso Peña 118", and 
"Alonso Peña 113" X"Alonso Peña 121", to analyze the affinity phenomenon,

(ii) $1 F_{1}$ intervarietal hybrid: "Alonso Peña 114 " $\times$ "Chinese Spring", to ascertain the source of chromosome markers between the parents in the above-mentioned hybrids.

The lines "Alonso Peña 113", "Alonso Peña 114", "Alonso Peña 118" and "Alonso Peña 121"
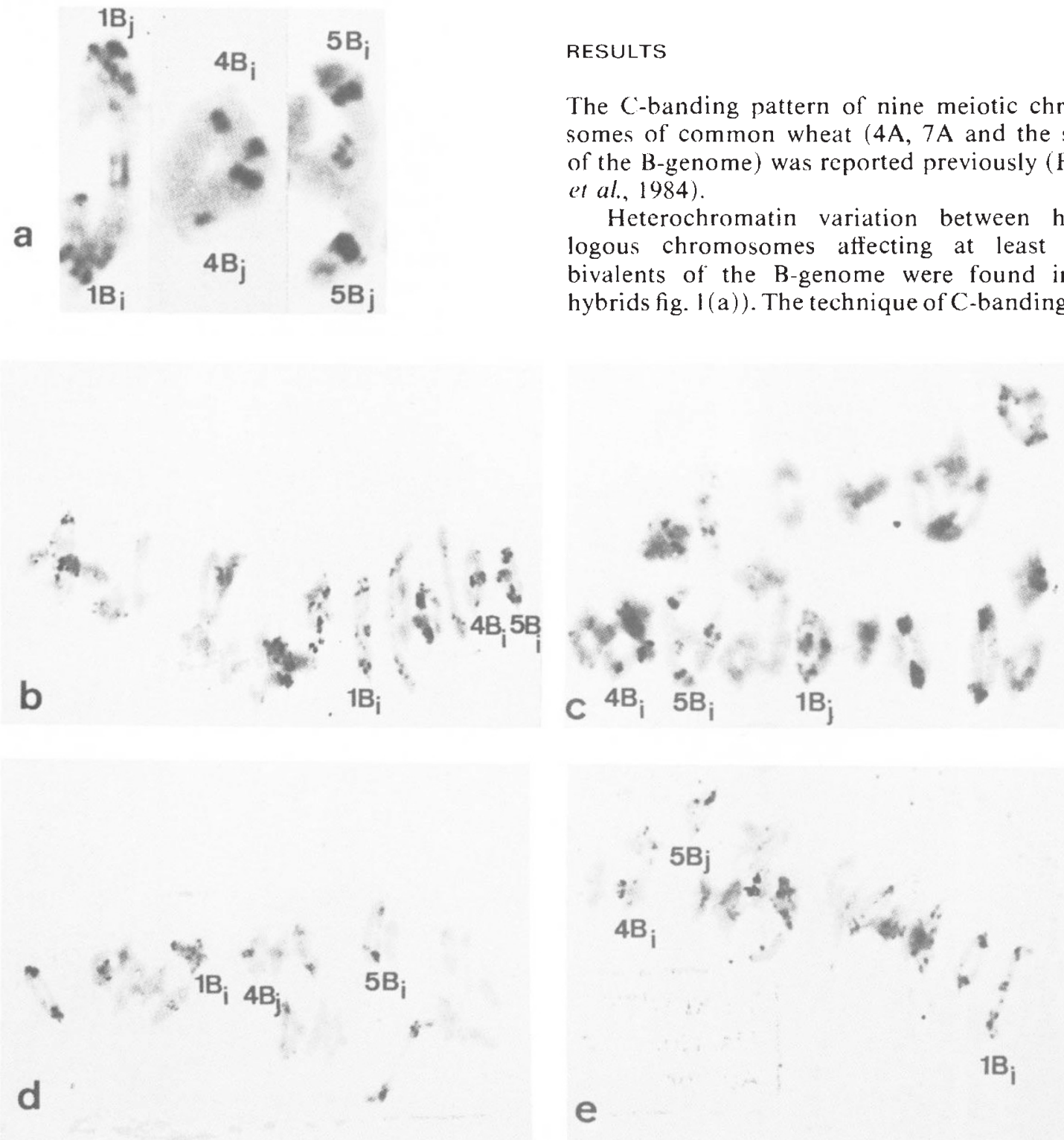

were derived and have been maintained by selfcrossing from the first generation after the backcross: [( T. aestivum L. cv " $\mathrm{H}-53$ " $\times$ S. cereale L.) $\times$ T.aestivum L. cv. "H-53"] $]^{\mathrm{n}}$ and had $n=26$.

Meiotic observations were made in nondistorted pollen mother cells at first metaphase that were fixed in acetic acid-alcohol $(1: 3)$ and stained by the C-banding method previously reported (Jouve et al., 1980a). Preparations were made permanent using Depe- $X$ mounting media.

\section{RESULTS}

The C-banding pattern of nine meiotic chromosomes of common wheat $(4 \mathrm{~A}, 7 \mathrm{~A}$ and the seven of the B-genome) was reported previously (Ferrer et al., 1984).

Heterochromatin variation between homologous chromosomes affecting at least three bivalents of the $\mathrm{B}$-genome were found in the hybrids fig. 1(a)). The technique of C-banding used 
revealed repeatable patterns of bands in the wheat bivalents. The heterochromatin polymorphism differentiating the karyotypes of the varieties used in the crosses were easily distinguished by the pycnotically asymmetrical aspect of the following bivalents:

1B. It exhibits a subtelomeric faint band in the short arm in one chromosome which was absent in its corresponding homologue.

$4 \mathrm{~B}$. It shows a pericentromeric band around the centromere more intensely stained in one of the chromosomes than in its homologue.

$5 \mathrm{~B}$. It presents one intercalary band on the long arm of one chromosome which was absent in its homologue.

These heterochromatic differences resulted in excellent chromosome markers. The three individual chromosomes carrying the most intensely stained heterochromatic regions have been named $i\left(1 \mathrm{~B}_{i}, 4 \mathrm{~B}_{i}\right.$ and $\left.5 \mathrm{~B}_{i}\right)$, and there corresponding homologues have been named $j\left(1 \mathrm{~B}_{j}, 4 \mathrm{~B}_{j}\right.$ and $5 \mathrm{~B}_{j}$ ).

Depending on the centromere co-orientation in the metaphase plates, four types of distributions could be found, which are illustrated in fig. 1(b) to $1(\mathrm{e})$ :

$$
\begin{array}{cc}
\frac{1 \mathrm{~B}_{i}-4 \mathrm{~B}_{i}-5 \mathrm{~B}_{i}}{1 \mathrm{~B}_{j}-4 \mathrm{~B}_{j}-5 \mathrm{~B}_{j}} & \frac{1 \mathrm{~B}_{j}-4 \mathrm{~B}_{i}-5 \mathrm{~B}_{i}}{1 \mathrm{~B}_{i}-4 \mathrm{~B}_{j}-5 \mathrm{~B}_{j}} \\
\frac{1 \mathrm{~B}_{i}-4 \mathrm{~B}_{j}-5 \mathrm{~B}_{i}}{1 \mathrm{~B}_{j}-4 \mathrm{~B}_{i}-5 \mathrm{~B}_{j}} & \frac{1 \mathrm{~B}_{i}-4 \mathrm{~B}_{i}-5 \mathrm{~B}_{j}}{1 \mathrm{~B}_{j}-4 \mathrm{~B}_{j}-5 \mathrm{~B}_{i}}
\end{array}
$$

The interdependence of centromere co-orientation of bivalents can be deduced if deviations from assortative ratios $1: 1: 1: 1$ is observed. Data on type and frequencies of distribution of centromeres for the hybrids having "Alonso Peña 113" as common parent are registered in table 1 . It should be pointed out that $1 \mathrm{~B}_{i}-4 \mathrm{~B}_{i}-5 \mathrm{~B}_{i} / 1 \mathrm{~B}_{j}-4 \mathrm{~B}_{j}-5 \mathrm{~B}_{j}$ co-orientation type occurs more frequently than remaining types for the three hybrids analyzed. In all cases the observed values differed significantly from random distributions. However, no significant differences were observed when the tendencies towards one or another type of co-orientations among the hybrids were compared by means of a contingency chi-square test $\left(\chi^{2}=3 \cdot 12 ; \mathrm{df}=6\right.$; $0.70<\mathrm{P}<0 \cdot 80$ ).

The source of each one of the chromosomes involved in the bivalents has been investigated by means of the analysis of C-banding pattern of corresponding chromosomes in other hybrids having "Chinese Spring" as common parent (fig. 2).

Detailed observations on Giemsa-stained meiotic chromosomes of "Alonso Peña 114" $\times$ "Chinese Spring" hybrids plants were made on $1 \mathrm{~B}, 4 \mathrm{~B}$ and $5 \mathrm{~B}$ bivalents. The $\mathrm{C}$-banding pattern differences between the homologue were evident. Bivalent 1 B in "Chinese Spring" $x$ "Alonso Peña 114 " lacks of the intercalary band on its short arm, which was always observed in only one chromosome of the bivalent $1 \mathrm{~B}$ in "Chinese Spring" $\times$ "Alonso Peña 113" and "Alonso Peña 113" $\times$ "Alonso Peña 121". Consequently, the chromosome $1 \mathrm{~B}$ having the characteristic intercalary band was assigned to "Alonso Peña 113". Similarly, chromosome 4B in "Alonso Peña 113" was identified by its wider pericentromeric and thiner

\begin{tabular}{|c|c|c|c|c|c|c|c|c|}
\hline \multirow{2}{*}{$\begin{array}{l}\text { Co-orientation } \\
\text { of bivalents }\end{array}$} & \multicolumn{2}{|c|}{ "CS" X"AP-113" } & \multicolumn{2}{|c|}{ "AP-113" ×"AP-118" } & \multicolumn{2}{|c|}{ "AP-113" ×"AP-121" } & \multicolumn{2}{|c|}{ Total of the hybrids } \\
\hline & Obs & Exp & Obs & Exp & Obs & Exp & Obs & Exp \\
\hline$\frac{1 \mathrm{~B}_{i}-4 \mathrm{~B}_{i}-5 \mathrm{~B}_{i}}{1 \mathrm{~B}_{j}-4 \mathrm{~B}_{j}-5 \mathrm{~B}_{j}}$ & 100 & 50 & 16 & $9 \cdot 25$ & 52 & $31 \cdot 25$ & 168 & $90 \cdot 5$ \\
\hline$\frac{1 B_{j}-4 B_{i}-5 B_{i}}{1 B_{i}-4 B_{i}-5 B_{j}}$ & 34 & 50 & 6 & $9 \cdot 25$ & 26 & $31 \cdot 25$ & 66 & $90 \cdot 5$ \\
\hline$\frac{1 \mathrm{~B}_{i}-4 \mathrm{~B}_{i}-5 \mathrm{~B}_{i}}{1 \mathrm{~B}_{i}-4 \mathrm{~B}_{i}-5 \mathrm{~B}_{j}}$ & 32 & 50 & 7 & $9 \cdot 25$ & 20 & $31 \cdot 25$ & 59 & $90 \cdot 25$ \\
\hline$\frac{1 \mathrm{~B}_{i}-4 \mathrm{~B}_{i}-5 \mathrm{~B}_{j}}{1 \mathrm{~B}_{j}-4 \mathrm{~B}_{j}-5 \mathrm{~B}_{i}}$ & 34 & 50 & 8 & $9 \cdot 25$ & 27 & $31 \cdot 25$ & 69 & $90 \cdot 5$ \\
\hline$\chi^{2}$ random distribution & $66 \cdot 72$ & & $6 \cdot 78$ & & $18 \cdot 84$ & & $89 \cdot 05$ & \\
\hline & 3 & & 3 & & 3 & & 3 & \\
\hline Significance level & $P<0.001$ & & $0 \cdot 05$ & $0 \cdot 10$ & $P<0.001$ & & $P<0.001$ & \\
\hline $\begin{array}{l}\chi^{2} \text { contingency test } \\
\text { df } \\
\text { Significance level }\end{array}$ & $\begin{array}{l}3 \cdot 12 \\
6 \\
0 \cdot 70<P<\end{array}$ & 0.80 & & & & & & \\
\hline
\end{tabular}

Table 1 Analysis of $1 \mathrm{~B}, 4 \mathrm{~B}$ and $5 \mathrm{~B}$ centromere co-orientation in three intervarietal hybrids of common wheat. 

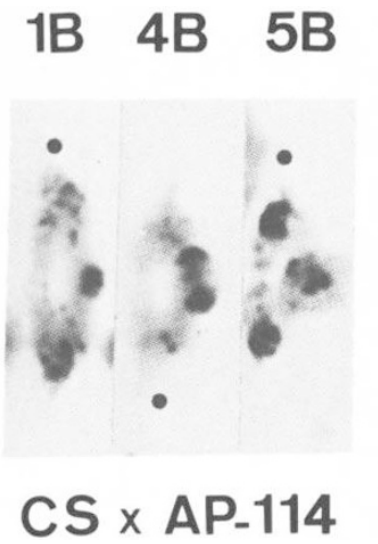
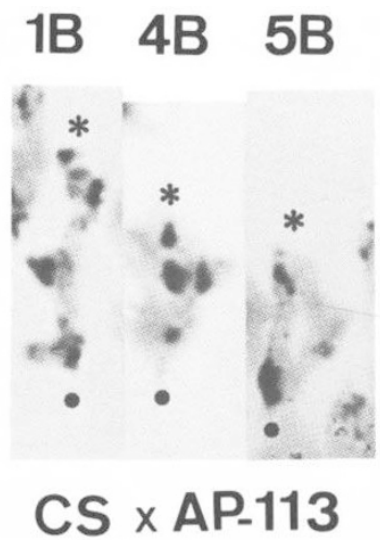
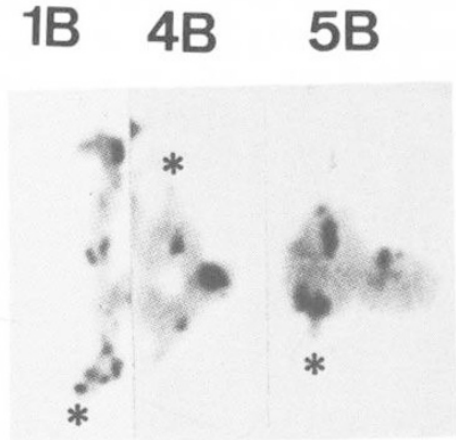

AP-113 x AP-121

Figure 2 C-banded meiotic chromosomes of the "Chinese Spring" $x$ "Alonso Peña 114", "Chinese Spring" $x$ "Alonso Peña I13" and "Alonso Peña 121" hybrids. Points and stars indicate respectively the location of "Chinese Spring" and "Alonso Peña 113 " chromosomes which are each present in two different hybrids.

subtelomeric C-bands than in the homologue of the other variety. Finally, the long arm subterminal band in only one 5B chromosome in "Chinese Spring" $\times$ "Alonso Peña 113", "Alonso Peña 113" " "Alonso Peña 118" and "Alonso Peña $113 " \times$ "Alonso Peña 121", seems to demonstrate that chromosome 5B lacking that characteristic band is coming from "Alonso Peña 113".

\section{DISCUSSION}

Details of the karyotype of cereals made during recent years using Giemsa staining techniques have revealed the existence of intervarietal variation in the amount and/or distribution of heterochromatin (Weimarck, 1975; Lelley et al., 1978; Jouve et al., 1980b; Seal, 1982; Teoh et al., 1983; Ferrer et al., 1984). Recently, Endo and Gill (1984) carried out the analysis of heterochromatin distribution and structural differentiation of somatic chromosomes of "Chinese Spring" and four other common wheat cultivars. They observed a high frequency of N-band polymorphism, especially for most of the $B$ genome chromosomes, that seems to affect the level of chromosome pairing. Leaving out the relationship of heterochromatin with chromosome pairing that is beyond the scope of this paper, it is apparent that intervarietal variation in C-banding pattern in wheat is of applied interest in many cytogenetic studies as morphological markers.

The most significant observation in the present study is the affinity among chromosomes having in common similar variation in their heterochromatic pattern $\left(1 \mathrm{~B}_{i}-1 \mathrm{~B}_{i}-5 \mathrm{~B}_{i} / 1 \mathrm{~B}_{j}-4 \mathrm{~B}_{j}-5 \mathrm{~B}_{j}\right)$.
The greater frequency of centromere aggregation type corresponds with chromosomes carrying the more $(i)$ or the less $(j)$ dense regions of heterochromatin going to opposite poles.

Until now the possible affinity between chromosomes was deduced from observations of cases of "quasi-linkage", first reported by Michie (1953) and Wallace (1953), that is the preferential segregation of associated genes where loci are on non-homologous chromosomes (Wallace, 1958; 1961; Parsons, 1959; Phillips, 1964; Conner, 1966).

In our material, the most frequent type of centromere distribution does not correspond to migration to the same pole of parental centromeres. However, some kind of affinity amongst specific chromosomes coming from different parents in the hybrids has been observed. It does seem reasonable to conclude, in agreement with previous genetic observations, that affinity between non-homologous chromosomes could be due to structural causes. In the light of the present findings, it is conceivable that the preferential coaggregation of non-homologous chromosomes having special characteristics in their heterochromatic structure must reflect the spatial arrangement of chromosomes. Bennett et al. (1974, 1979) suggested previously that intranuclear fibrilar material (FM) observed in cereal pollen mother cells, may function in establishing or maintaining the spatial co-orientation of chromosomes which is a pre-requisite for normal meiotic pairing. Our results are compatible with the general idea of interchromosome spatial associations of Bennett and co-workers. Although, the relationship of heterochromatin variation with spatial arrangement of chromosomes at first metaphase is beyond 
the scope of this contribution, the effect of heterochromatin on affinity is suggested. This in turn, gives emphasis to the mechanical significance of heterochromatin during evolution in cereals.

Acknowledgement The authors thank the CAICYT of Spain for the award of a grant (No. 1558-82) to support this work.

\section{REFERENCES}

BENNETT, M. D., STERN, H. AND WOODWARD, M. (1974) Chromatin attachment to nuclear membrane of wheat pollen mother cells. Nature, 252, 395-396.

BENNETT, M. D., SMITH, J. B., SIMPSON, S. AND WELLS, B. 1979. Intranuclear fibrillar material in cereal pollen mother cells. Chromosoma, 71, 289-331.

CONNER, G. W. 1966. Preferential segregation in Mormoniella. Genetics, 54, $1041-1048$.

ENDO, T. R. AND GILL, B. S. 1984. Somatic karyotype, heterochromatin distribution, and nature of chromosome differentiation in common wheat, Triticum aestivum L. em Thell. Chromosome, 89, 361-369.

FERRER, E., GONZALEZ, J. M. AND JOUVE, N. 1984. Identification of C-banded chromosomes in meiosis of common wheat, Triticum aestivum. L. Theor. Appl. Genet., 67, 257261.

HWANG, Y. L. 1966. Sites of affinity and linear arrangement of genes on chromosome V of Saccharomyces. Can. J. Genet. Cytol., 8, 677-694.

JOUVE, N., DIEZ, N. AND RODRIGUEZ, M. 1980a. C-banding in $6 \mathrm{x}$-Triticale $\times$ Secale cereale L. Hybrid cytogenetics. Theor. Appl. Genet., 57, 75-79.

JOUVE, N., MONTALVO, D. AND SOLER, C. 1980b. Differential heterochromatic regions in homologous chromosomes of wheat. Cereal Res. Comm., 8, 599-603.

LELLEY, T., JOSIFEK, K. AND KALTSIKES, P. J. 1978. Polymorphism in the Giemsa C-banding pattern of rye chromosomes. Can. J. Genet. Cytol., 20, 307-312.

LINDEGREN, C. C. AND SHULT, E. E. 1956. Non-random assortment of centromeres with implications regarding random assortment of the chromosomes. Experientia, 12, 177-178.
LINDEGREN, C. C., LINDEGREN, G., SHULT, E. AND HWANG, Y. L. 1962. Centromeres, sites of affinity and gene loci on the chromosomes of Saccharomyces. Nature, 194, 260-265.

MICHEL, K. E. 1970. A test for "affinity" in maize. Heredity, $25,133-137$.

MICHIF, D. 1953. Affinity: a new genetic phenomenon in the house mouse. Nature, 171, 26-27.

MiChie, D. 1955. Affinity. Proc. Roy. Soc., B., 144, 241-259.

NARANJO, T. AND LACADENA, J. R. 1979. Analysis of centromere co-orientation in a rye-wheat derivate by means of C-banding. Chromosoma, 73, 227-235.

PARSONS, P. A. 1959. Possible affinity between linkage groups $\mathrm{V}$ and XIII of the house mouse. Genetica, 29, 304-311.

PHILLIPS, L. 1964. Cytogenetical evidence on the question of affinity in cotton. Heredity, 19, 21-26.

REES, H. ANI) JONES, G. H. 1967. Chromosome evolution in Lolium. Heredity, 22, 1-18.

RHOADES, M. M. 1942. Preferential segregation in maize. Genetics, 27, 395-407.

RHOADES, M. M. AND DEMPSEY, E. 1966. The effect of abnormal chromosome 10 on preferential segregation and crossing over in maize. Genetics, 53, 989-1020.

SEAL, A. G. 1982. C-banded wheat chromosomes in wheat and triticale. Theor. Appl. Genet., 63, 39-47.

SFICAS, A. G. 1963. Statistical analysis of chromosome distribution to the poles in interspecific hybrids with variable chromosome pairing. Genet. Res. 4, 266-75.

SHULT, E. E. AND LINDEGREN, C. C. 1957. Ortho-orientation: a new tool for genetical analysis. Genetica, 29, 58-82.

TEOH, S. B., MILLER, T. E. AND READER, S. M. 1983. Intraspecific variation in C-banded chromosomes of Aegilops comosa and Ae. speltoides. Theor. Appl. Genet. 65, 343-348.

WALLACE, M. E. 1953. Affinity: a new genetic phenomenon in the house mouse. Evidence from labotarory stocks. Nature, $171,27-28$.

WALLACE, M. A. 1958. Experimental evidence for a new genetic phenomenon. Phil. Trans. Roy. Soc. B., 241, 211-254.

WALLACE, M. E. 1959. An experimental test of the hypothesis of affinity. Genetica, 29, 243-255.

WALLACE, M. 1960. Possible cases of affinity in cotton. Heredity, 14, 263-274.

WALLACE, M. E. 1961. Affinity: evidence from crossing inbred lines of mice. Heredity, 16, 1-23.

Wallace, M. E. 1964. Affinity in cotton. Heredity, 20, 305-308.

WEIMARCK, A. 1975. Heretochromatin polymorphism in the rye karyotype as detected by the Giemsa C-banding technique. Hereditas, 79, 293-300. 